\title{
FUNGSI WRIGHT SEBAGAI SOLUSI ANALITIK PERSAMAAN DIFUSI-GELOMBANG FRAKSIONAL PADA MEDIA VISKOELASTIS
}

\author{
Ray Novita Yasa ${ }^{1 *}$, Agus Yodi Gunawan ${ }^{2}$ \\ ${ }^{1}$ Politeknik Siber dan Sandi Negara \\ ${ }^{2}$ Institut Teknologi Bandung \\ *Email Korespondensi: ${ }^{1}$ ray.novita@ poltekssn.ac.id
}

\begin{abstract}
A fractional diffusion-wave equations in a fractional viscoelastic media can be constructed by using equations of motion and kinematic equations of viscoelastic material in fractional order. This article concerns the fractional diffusion-wave equations in the fractional viscoelastic media for semi-infinite regions that satisfies signalling boundary value problems. Fractional derivative was used in Caputo sense. The analytical solution of the fractional diffusion-wave equation in the fractional viscoelastic media was solved by means of Laplace transform techniques in the term of Wright function for simple form solution. For general parameters, Numerical Inverse Laplace Transforms (NILT) was used to determine the solution.
\end{abstract}

Keywords: diffusion-wave, viscoelastic, Scott-Blair model, wright function, NILT.

\begin{abstract}
Abstrak. Dengan menggunakan persamaan gerak dan persamaan kinematik material viskoelastis dalam orde fraksional, dapat dikonstruksi persamaan difusi-gelombang berorde fraksional dalam media viskoelastis tersebut. Dalam artikel ini secara khusus akan dibahas mengenai persamaan difusi-gelombang fraksional pada media viskoelastis fraksional untuk daerah semi infinit yang memenuhi nilai batas signalling. Turunan fraksional yang digunakan turunan fraksional tipe Caputo. Solusi analitik dari persamaan diperoleh dengan menggunakan teknik transformasi Laplace, serta penggunaan fungsi Wright untuk mengarahkan solusi kedalam bentuk yang sederhana. Untuk parameter yang umum, metode Numerical Invers Laplace Transforms (NILT) digunakan untuk menentukan solusinya.
\end{abstract}

Kata Kunci: difusi-gelombang, viskoelastis, model Scott-Blair, fungsi wright, NILT.

\section{PENDAHULUAN}

Reologi dapat dipandang sebagai ilmu yang mempelajari tentang deformasi dan aliran material yang terjadi akibat adanya interaksi antara tegangan dan regangan pada material. Praktisnya, reologi berhubungan dengan perluasan mekanika untuk mengkarakterisasi aliran dari material yang menunjukkan sifat antara elastis sekaligus viskos, yang selanjutnya disebut sebagai material viskoelastis. Untuk menjelaskan bagaimana deformasi dan aliran material secara mekanik dibangunlah model viskoelastis yang linear, tetapi pada umumnya model linear ini efektif untuk diterapkan pada material dengan deformasi yang kecil, yaitu pada tegangan yang mengakibatkan regangan dibawah nilai $5 \times 10^{-2}$.

Hasil observasi Nutting [1] pada banyak material, disimpulkan bahwa formula umum untuk menyatakan hubungan tegangan $\sigma(t)$, regangan $(\triangle S)$, dan waktu adalah $\sigma(t) \sim C \triangle S . t^{-\alpha}$ dengan $\alpha \in(0,1)$ dan $C$ konstan, dan nilai $\alpha$ dekat ke $\frac{1}{2}$ pada banyak material. Hasil terse- 
but mendasari terbentuknya konsep model viskoelastis fraksional, dengan tujuan untuk menemukan hubungan tegangan dan regangan secara tepat pada kelas-kelas material yang lebih luas [2]. Model ini ternyata berhasil diterapkan untuk mendeskripsikan sifat-sifat Reologi dari material seperti organic glasses, elastomers, polyurethane, polyisobutylene, dan solid amorphous polymer [3].

Seiring banyaknya penggunaan material viskoelastis dalam kehidupan serta berkembangnya ilmu tentang material ini, semakin banyak pula masalah yang dapat dikaji. Salah satunya penelitian tentang persamaan difusi-gelombang berorde fraksional (selanjutnya ditulis difusi-gelombang fraksional) pada media viskoelastis berorde fraksional. Permasalahan elekromagnetik, akustik, dan respon mekanik suatu material dapat dimodelkan secara akurat menggunakan persamaan difusi-gelombang [4]. Karena itu penelitian dengan topik persamaan difusi-gelombang fraksional menjadi sangat bermanfaat. Penelitian dengan topik ini juga memiliki potensi untuk berkembang menjadi penemuan solusi analitik dengan parameter yang tidak dibatasi.

Beberapa penelitian terdahulu dilakukan oleh Mainardi, Luchko, dan Pagnini [5] yang membangun persamaan difusi fraksional (dalam ruang dan waktu), dengan tujuan mencari solusi umumnya yang memenuhi kondisi batas Cauchy. Konsep turunan fraksional yang digunakan adalah turunan fraksional tipe Caputo. Teknik yang digunakan untuk mendapatkan solusi umum adalah dengan transformasi Fourier-Laplace, penggunaan Green function serta merepresentasikannya dalam bentuk integral Mellin-Barnes. Penelitian lanjutan dengan topik yang sama juga dilakukan, tetapi menggunakan teknik yang berbeda dalam mencari solusinya yaitu dengan fungsi Fox-H [6]. Pengkajian dilanjutkan oleh Povstenko yang membahas persamaan difusi-gelombang fraksional pada sebuah tabung yang cukup panjang dengan koordinat $r, \varphi$, dan $z$, kondisi batas yang digunakan adalah kondisi batas Dirichlet dan kondisi batas Neumann. Solusi dari persamaan tersebut diperoleh hanya dengan menggunakan transformasi Laplace, kemudian mengarahkan solusi kedalam bentuk fungsi generalisai Mittag-Leffler [7]. Selain menggunakan teknik transformasi Laplace, permasalahan difusi-gelombang fraksional dapat diselesaikan dengan menggunakan metode diskritisasi seperti pada [8] dan dapat juga diselesaikan dengan metode elemen hingga seperti pada [9].

Penelitian sebelumnya mengkaji difusi-gelombang fraksional pada media yang secara spesifik tidak viskoelastis. Dalam penelitian ini persamaan difusi-gelombang fraksional yang secara khusus dikaji pada media viskoelastis fraksional dengan mengunakan konsep turunan fraksional Caputo. Nilai batas yang akan digunakan adalah nilai batas signalling. Media viskoelastis fraksional yang dipandang adalah yang homogen antar elemennya dan dimodelkan oleh model Scott-Blair.

Solusi analitik dari persamaan difusi-gelombang fraksional umumnya dicari menggunakan teknik transformasi Laplace. Penyelesaian dari persamaan yang diperoleh dalam penelitian ini akan diarahkan pada penggunakan fungsi Wright untuk parameter tertentu yang dibatasi. Fungsi Wright sudah banyak diterapkan misalkan pada penelitian yang terdapat pada [10]. Untuk parameter yang umum akan digunakan metode generalisasi Numerical Invers Laplace Transforms (NILT). Perbandingan antara solusi analitik dan solusi numerik disajikan dengan menggunakan grafik. 


\section{TURUNAN FRAKSIONAL, FUNGSI KHUSUS TERKAIT, DAN MODEL SCOTT-BLAIR}

\subsection{Turunan Fraksional}

Definisi 1 [11] Sebuah fungsi $f(t), t>0$, dikatakan berada pada ruang fungsi $C_{\mu}, \mu \in \mathbb{R}$ jika terdapat bilangan real $p>\mu$ sehinggaf $(t)=t^{p} f_{1}(t)$ dimana $f_{1}(t) \in C(0, \infty)$, dan dikatakan berada pada ruang fungsi $C_{\mu}^{m}$ jika $f^{m} \in C_{\mu}, m \in \mathbb{N}$.

Contoh 1 Misalkan $f(t)=t^{4}-3 t$ yang didefinisikan pada daerah $t>0$, fungsi ini berada pada ruang fungsi $C_{-1}$ karena dapat ditulis menjadi $f(t)=t^{1}\left(t^{3}-3\right)$ dengan $1>-1$, dimana $f_{1}(t)=\left(t^{3}-3\right) \in C(0, \infty)$, dengan kata lain $t^{3}-3 t$ kontinu sepanjang daerah $t>0$.

Definisi 2 [11]Turunan fraksional Caputo dari fungsi $f(t) \in C_{-1}^{m}, m \in \mathbb{N}, t>0$, didefinisikan sebagai

$$
{ }_{0} D_{t}^{\beta} f(t)= \begin{cases}{ }_{0} I^{m-\beta} \frac{d^{m}}{d t^{m}} f(t), & \text { jika } m-1<\beta<m, \\ \frac{d^{m}}{d t^{m}} f(t), & \text { jika } \beta=m .\end{cases}
$$

Definisi (2) menjelaskan bahwa turunan fraksional Caputo bagi fungsi yang memenuhi $f(t) \in C_{-1}^{m}, m \in \mathbb{N}, t>0$, adalah sebagaimana turunan biasa seperti yang dikenal umumnya. Apabila turunan $\beta$ bernilai fraksional dengan kondisi $m-1<\beta<m$ maka turunan ${ }_{0} D_{t}^{\beta} f(t)={ }_{0} I^{m-\beta} \frac{d^{m}}{d t^{m}} f(t)$ dengan ${ }_{0} I^{m-\beta} \frac{d^{m}}{d t^{m}} f(t)=\frac{1}{\Gamma(m-\beta)} \int_{t}^{0} \frac{f^{(m)}(\tau)}{(t-\tau)^{\beta+1-m}} d \tau$ [12].

Definisi 3 [11] Misalkan $\mathcal{L}$ adalah operator Laplace, dan $\mathcal{L}\{f(t) ; s\}=\widetilde{f}(s)$ untuk $t \geq 0$ dan $s \in \mathbb{C}$, transformasi Laplace untuk turunan dengan orde bilangan asli $n$ dari fungsi $f(t)$ adalah

$$
\mathcal{L}\left\{f^{n}(t) ; s\right\}=s^{n} \widetilde{f}(s)-\sum_{k=0}^{n-1} s^{n-k-1} f^{k}(0) .
$$

Dengan menggunakan persamaan (1), untuk $m-1<\alpha<m$ mudah untuk ditunjukkan bahwa berlaku persamaan (2) yang selanjutnya akan digunakan sebagai persamaan transformasi Laplace bagi turunan fraksional.

$$
\mathcal{L}\left\{{ }_{0} D_{t}^{\alpha} f(t) ; s\right\}=s^{\alpha} \widetilde{f}(s)-\sum_{k=0}^{m-1} s^{\alpha-k-1} f^{k}(0) .
$$

\subsection{Fungsi Khusus Terkait}

Definisi 4 [13] Fungsi Mittag-Leffler merupakan sebuah fungsi kompleks yang bergantung pada dua parameter kompleks $\alpha$ dan $\beta$, yang direpresentasikan oleh deret yang konvergen pada keseluruhan bidang kompleks sebagai

$$
E_{\alpha, \beta}(z):=\sum_{n=0}^{\infty} \frac{z^{n}}{\Gamma(\alpha n+\beta)}, \quad \operatorname{Re}(\alpha)>0, \beta>0, z \in \mathbb{C} .
$$

$e_{\alpha, \beta}(t ; \lambda):=t^{\beta-1} E_{\alpha, \beta}\left(-\lambda t^{\alpha}\right), \operatorname{Re}(\alpha)>0, \beta>0, \lambda \in \mathbb{C}, t \geq 0$, sebagai fungsi khusus dari 
fungsi Mittag-Leffler.

Transformasi Laplace pada $e_{\alpha, \beta}(t ; \lambda)$ akan menghasilkan

$$
\mathcal{L}\left\{e_{\alpha, \beta}(t ; \lambda), s\right\}=\frac{s^{\alpha-\beta}}{s^{\alpha}+\lambda} .
$$

Wright (1940) membangun suatu generalisasi dari fungsi Bessel untuk orde lebih dari 1, yang kemudian diperluas untuk orde yang lebih besar dari 1 [14].

Definisi 5 [12] Fungsi Wright adalah fungsi kompleks yang direpresentasikan oleh deret

$$
W_{\lambda, \mu}(z):=\sum_{n=0}^{\infty} \frac{z^{n}}{n ! \Gamma(\lambda n+\mu)}, \quad \lambda>-1, \mu \in \mathbb{C} .
$$

Dari bentuk pendefinisiannya, jelas bahwa fungsi Wright merupakan fungsi menyeluruh. Representasi integral dari fungsi ini adalah

$$
W_{\lambda, \mu}(z):=\frac{1}{2 \pi i} \int_{H a} e^{\sigma+z \sigma^{-\lambda}} \frac{d \sigma}{\sigma^{\mu}}, \quad \lambda>-1, \mu \in \mathbb{C},
$$

dimana $H a$ menotasikan lintasan integrasi Hankel. Sifat-sifat fungsi Wright, teorema yang menyertai, dan beberapa penerapannya merujuk pada [18][10].

Selanjutnya akan disajikan teorema yang menjamin kewujudan dan ketunggalan solusi dari sebuah persamaan diferensial fraksional yang buktinya dapat dilihat pada [13].

Teorema 1 [13] Pandang masalah nilai awal berikut

$$
\begin{aligned}
{ }_{0} D_{t}^{\sigma_{n}} y(t) & =f(t, y) \\
{\left[{ }_{0} D_{t}^{\sigma_{k-1}} y(t)\right]_{t=0} } & =b_{k}, \quad k=1,2, \ldots, n \\
\sigma_{k} & =\sum_{j=1}^{k} a_{j}, \quad j=1,2, \ldots, n \\
0 & <a_{j} \leq 1 .
\end{aligned}
$$

Misal $f(t, y)$ adalah sebuah fungsi kontinu yang terdefinisi pada domain $G$, yang memenuhi kondisi Lipschitz di $G$ terhadap variabel y, yaitu $\left|f\left(t, y_{1}\right)-f\left(t, y_{2}\right)\right| \geq A\left|y_{1}-y_{2}\right|$, sehingga $|f(t, y)| \leq M<\infty, \forall(t, y) \in G$. Misalkan juga $K \geq \frac{M h^{\sigma n-\sigma_{1}+1}}{\Gamma\left(1+\sigma_{n}\right)}$, maka akan ada sebuah solusi tunggal $y(t)$ dalam region $R(h, K)$ dari masalah nilai awal tersebut.

Persamaan difusi-gelombang fraksional yang akan dikonstruksi dan diselesaikan dalam penelitian ini menggunkan nilai batas Signalling. Dalam [15] nilai batas ini adalah masalah persamaan diferensial dengan kondisi batas

$$
r\left(0^{+}, t\right)=r_{0}(t), \lim _{x \rightarrow \infty} r(x, t)=0, \quad t>0
$$


dan kondisi awal

$$
r\left(x, 0^{+}\right)=\left.\frac{\partial}{\partial t} r(x, t)\right|_{t=0^{+}}=0, \quad x>0 .
$$

Ketika melakukan invers transformasi Laplace untuk fungsi yang rumit, biasanya sulit untuk dapat menemukan solusi analitiknya. Salah satu metode yang dapat membantu mendapatkan invers transformasi Laplace adalah metode NILT. Metode ini didasarkan pada invers langsung transformasi laplace dengan kernel $e^{s t}$ dalam integral Bromwich, serta diikuti pendekatan numerik untuk melakukan pengintegralan. Metode NILT dipilih berdasarkan hasil [16] yang mengatakan bahwa algoritma metode NILT efektif dan reliabel untuk masalah persamaan diferensial fraksional, dan sangat mudah digunakan untuk menyelesaikan masalah persamaan diferensial berorde fraksional rumit.

Misalkan $\mathcal{L}\{f(t)\}=F(s), t>0, s \in \mathbb{C}$, metode NILT akan menghasilkan

$$
f(t)=\frac{e^{\operatorname{Re}(z) t}}{m t}\left(\frac{F(\operatorname{Re}(z))}{2}+\sum_{k=1}^{\infty}\left\{\operatorname{Re}(F(z)) \cos \left(\frac{k \pi}{m}\right)-\sin \left(\frac{k \pi}{m}\right) \operatorname{Im}(F(z))\right\}\right)
$$

dengan $z=p+i \frac{k \pi}{m t}$, sebagai hampiran numerik dari invers transformasi Laplace dari $F(s)$ dengan metode NILT. Galat untuk metode ini yaitu $\epsilon(p t, m) \approx M e^{-2 m p t}, M$ adalah nilai maksimum mutlak dari $f(t)$ pada domainnya [19]. Untuk mengetahui lebih lanjut bagaimana metode NILT dibangun beserta contoh-contoh penerapannya terdapat pada [17].

\subsection{Model Scott-Blair}

Model Scott-Blair didasari oleh adanya model Hooke dan model Newton yang masingmasing terdiri dari elemen spring $(\sigma(t)=E \varepsilon(t))$ dan dashpot $(\sigma(t)=\eta \dot{\varepsilon}(t))$. Elemen yang digunakan untuk mendeskripsikan material viskoelastis fraksional disebut elemen fraksional. Model Scott-Blair memiliki bentuk seperti pada (Gambar 1.). Dengan E adalah parameter konstan dari elemen fraksional, $\eta$ adalah konstanta viskositas material, $\tau=\frac{\eta}{E}$, waktu relaksasi, $\alpha$ adalah orde fraksional dari operator derivatif terhadap waktu.

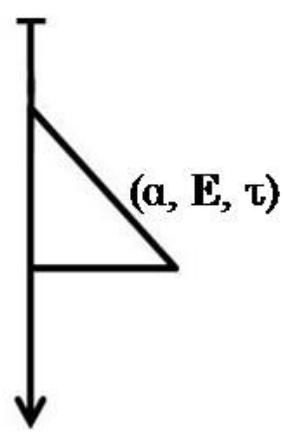

Gambar 1. Model Scott-blair yang elemennya merupakan modifikasi dari elemen spring dan elemen dashpot pada model linear 
Hubungan tegangan dan regangan dari sebuah elemen fraksional dinyatakan oleh

$$
\sigma(t)=E \tau^{\alpha} \frac{d^{\alpha}}{d t^{\alpha}} \varepsilon(t), \quad 0<\alpha<1
$$

Perhatikan bahwa, elemen fraksional menjadi elemen linier spring apabila parameter $\alpha=0$ dan menjadi elemen linier dashpot apabila parameter $\alpha=1$.

\subsection{Konstruksi Persamaan Untuk Model Scott-Blair}

Model ini hanya memiliki satu elemen fraksional, akibatnya hubungan tegangan dan regangan akan sama dengan persamaan (6). Dengan menuliskan ulang persamaannya yaitu

$$
\sigma(t)=E \tau^{\alpha} \frac{d^{\alpha}}{d t^{\alpha}} \varepsilon(t), \quad 0<\alpha<1 .
$$

Transformasi Laplace pada persamaan (6) menghasilkan $\widetilde{\sigma}(s)=E \tau^{\alpha} s^{\alpha} \widetilde{\varepsilon}(s)$. Pada [12] hubungan tegangan dan regangan dalam transformasi Laplace dituliskan dengan $\widetilde{\varepsilon}(s)=s \widetilde{J}(s) \widetilde{\sigma}(s)$ dan $\widetilde{\sigma}(s)=s \widetilde{G}(s) \widetilde{\varepsilon}(s)$. Dengan mensubstitusikan persamaan hubungan tegangan ke dalam persamaan (6) akan diperoleh $\widetilde{\sigma}(s)=E \tau^{\alpha} s^{\alpha+1} \widetilde{J}(s) \widetilde{\varepsilon}(s)$. Tanpa mengurangi keumuman, asumsikan bahwa $\sigma(t) \neq 0$, sehingga $\widetilde{\sigma}(s) \neq 0$. Akibatnya $\widetilde{J}(s)=\frac{1}{E \tau^{\alpha} s^{\alpha+1}}$, sehingga diperoleh $\widetilde{G}(s)=E \tau^{\alpha} s^{\alpha-1}$. Invers Laplace pada $\widetilde{J}(s)$ dan $\widetilde{G}(s)$ menghasilkan fungsi material untuk model ini yaitu

$$
\begin{gathered}
J(t)=\frac{t^{\alpha}}{E \tau^{\alpha} \Gamma(1+\alpha)}, \\
G(t)=\frac{E \tau^{\alpha} t^{-\alpha}}{\Gamma(1-\alpha)} .
\end{gathered}
$$

\section{KONSTRUKSI PERSAMAAN DIFUSI-GELOMBANG FRAKSIONAL}

Saat $t>0$ difusi-gelombang berorde fraksional terjadi pada sebuah batang viskoelastis semi-infinite, yang homogen dengan massa jenis $\rho$. Notasikan input gangguan pada ujung batang $\left(x=0^{+}\right)$sebagai $r_{0}(t)$, dan output pada posisi $x$ saat $t$ sebagai $r(x, t)$. Kondisi semiinfinite mengakibatkan masalah fraksional difusi-gelombang dipandang sebagai masalah nilai batas signalling[15]. Hubungan tegangan dan regangan dengan fungsi $r(x, t)$ disajikan pada [12] yaitu $\frac{\partial}{\partial x} \sigma(x, t)=\rho \frac{\partial^{2}}{\partial t^{2}} r(x, t)$ dan $\varepsilon(x, t)=\frac{\partial}{\partial x} r(x, t)$. Dengan menuliskan keduanya dalam bentuk turunan fraksional Caputo diperoleh

$$
\frac{\partial}{\partial x} \sigma(x, t)=\rho \frac{\partial^{\nu}}{\partial t^{\nu}} r(x, t), \quad 0<\nu \leq 2
$$

sebagai persamaan gerak, dan

$$
\varepsilon(x, t)=\frac{\partial}{\partial x} r(x, t)
$$

sebagai persamaan kinematik. 
Dalam suatu persamaan difusi-gelombang berorde fraksional, kecepatan rambat gelombang $(c)$, dapat diperoleh dengan menggunakan formula $c=\frac{1}{\sqrt{\rho J\left(0^{+}\right)}}$. Dapat ditunjukkan bahwa $J\left(0^{+}\right)=0$ untuk semua model, akibatnya nilai $c$ akan menuju takhingga. Karena sulit untuk memahami pergerakan gelombang dalam material yang berdeformasi ketika kecepatannya menuju tak hingga, maka $c$ diasumsikan berhingga. Berdasarkan hal tersebut maka dalam pembahasan selanjutnya $c$ diasumsikan berhingga.

\subsection{Konstruksi Persamaan Difusi-Gelombang Pada Model Scott-Balir}

Akan dituliskan kembali hasil konstruksi model fraksional Scott-Blair yaitu

$$
\sigma(x, t)=E \tau^{\alpha} \frac{\partial^{\alpha}}{\partial t^{\alpha}} \varepsilon(x, t), \quad 0<\alpha<1 .
$$

Turunkan kedua ruas terhadap $x$, sehingga diperoleh

$$
\frac{\partial}{\partial x} \sigma(x, t)=E \tau^{\alpha} \frac{\partial^{\alpha}}{\partial t^{\alpha}}\left[\frac{\partial}{\partial x} \varepsilon(x, t)\right]
$$

Substitusi persamaan (8a) dan (8b) ke persamaan (10), diperoleh

$$
\frac{\partial^{\nu}}{\partial t^{\nu}} r(x, t)=\frac{E \tau^{\alpha}}{\rho} \frac{\partial^{\alpha}}{\partial t^{\alpha}}\left[\frac{\partial^{2}}{\partial x^{2}} r(x, t)\right], \quad 0<\alpha<1,0<\nu \leq 2 .
$$

Persamaan (11) adalah Persamaan Difusi-Gelombang Pada Model Scott-Blair dengan kondisi batas (4a) dan kondisi awal (4b).

\subsection{Solusi Persamaan Difusi-Gelombang Pada Model Scott-Balir}

Dengan menggunakan persamaan (2), transformasi Laplace dari ruas kiri persamaan (11) untuk $0<\nu \leq 1$ akan diperoleh

$$
\mathcal{L}\left\{\frac{\partial^{\nu}}{\partial t^{\nu} r(x, t), s}\right\}=s^{\nu} \widetilde{r}(x, s)-s^{\nu-1} r\left(x, 0^{+}\right) .
$$

Persamaan (4b) memberikan informasi bahwa $r\left(x, 0^{+}\right)=0$, maka

$$
\mathcal{L}\left\{\frac{\partial^{\nu}}{\partial t^{\nu} r(x, t), s}\right\}=s^{\nu} \widetilde{r}(x, s) .
$$

Untuk $1<\nu \leq 2$

$$
\mathcal{L}\left\{\frac{\partial^{\nu}}{\partial t^{\nu} r(x, t), s}\right\}=s^{\nu} \widetilde{r}(x, s)-s^{\nu-1} r\left(x, 0^{+}\right)-\left.s^{\nu-2} \frac{\partial}{\partial t} r(x, t)\right|_{t=0^{+}} .
$$


Persamaan (4b) memberikan informasi bahwa $r\left(x, 0^{+}\right)=\left.\frac{\partial}{\partial t} r(x, t)\right|_{t=0^{+}}=0$, maka persamaan (13) akan menjadi bentuk

$$
\mathcal{L}\left\{\frac{\partial^{\nu}}{\partial t^{\nu} r(x, t), s}\right\}=s^{\nu} \widetilde{r}(x, s)
$$

Dengan demikian untuk $0<\nu \leq 2$ juga akan berlaku

$$
\mathcal{L}\left\{\frac{\partial^{\nu}}{\partial t^{\nu} r(x, t), s}\right\}=s^{\nu} \widetilde{r}(x, s) .
$$

Mengunakan konsep yang sama, untuk $0<\alpha<1$ diperoleh

$$
\mathcal{L}\left\{\frac{\partial^{\alpha}}{\partial t^{\alpha}}\left(\frac{\partial^{2}}{\partial x^{2}} r(x, t)\right)\right\}=s^{\alpha} \frac{\partial^{2}}{\partial x^{2}} \widetilde{r}(x, s) .
$$

Akibatnya transformasi Laplace pada persamaan (11) adalah

$$
\frac{\partial^{2}}{\partial x^{2}} \widetilde{r}(x, s)-\rho \frac{s^{\nu}}{E \tau^{\alpha} s^{\alpha}} \widetilde{r}(x, s)=0
$$

Karena $\widetilde{r}\left(0^{+}, s\right)=\widetilde{r}_{0}(s) \operatorname{dan} \lim _{x \rightarrow \infty} \widetilde{r}(x, s)=0$, diperoleh

$$
\widetilde{r}(x, s)=\widetilde{r}_{0}(s) e^{-x \sqrt{\frac{\rho}{E \tau^{\alpha}}} s \frac{\nu-\alpha}{2}} .
$$

Misal $\widetilde{G}(x, s)=e^{-x \sqrt{\frac{\rho}{E \tau^{\alpha}}} s^{\frac{\nu-\alpha}{2}}}$, maka solusi $r(x, t)$ diperoleh

$$
r(x, t)=r_{0}(t) *(G(x, t)),
$$

notasi $*$ merupakan notasi konvolusi Laplace.

Dalam artikel ini, solusi analitik diperoleh dengan membatasi parameter $\nu$ dan $\alpha$ yang menemuhi $\alpha<\nu<\alpha+2$. Untuk parameter $\alpha$ dan $\nu$ yang lain akan digunakan pendekatan numerik dengan metode NILT untuk menghampiri solusi $r(x, t)$.

3.3. Solusi $r(x, t)$ untuk $\alpha<\nu<\alpha+2$

Dengan menuliskan $\widetilde{G}(x, s)=e^{-x \sqrt{\frac{\rho}{E \tau^{\alpha}}} s^{\frac{\nu-\alpha}{2}}}$, invers transformasi Laplace dari $\widetilde{G}(x, s)$ dalam bentuk integral Bromwich adalah

$$
G(x, t)=\frac{1}{2 \pi i} \int_{B r} e^{s t} e^{-x \sqrt{\frac{\rho}{E \tau^{\alpha}}} s^{\frac{\nu-\alpha}{2}}} d s .
$$

Metode Nigmatullin untuk persamaan diferensial fraksional akan diterapkan pada persamaan (17) melalui permisalan $\varphi=s t, p=\frac{\nu-\alpha}{2}, z=x \sqrt{\frac{\rho}{E \tau^{\alpha}}} t^{-p}$, sehingga persamaan (17) dapat 
ditulis ulang menjadi

$$
\begin{aligned}
G(x, t) & =\frac{1}{2 \pi i} \frac{1}{t} \int_{H a} e^{\varphi-z \varphi^{p}} d \varphi, \quad 0<p<1 \\
& =\frac{1}{t} \frac{1}{2 \pi i} \int_{H a} e^{\varphi-z \varphi^{p}} d \varphi \\
& =\frac{1}{t} W_{-p, 0}(-z) .
\end{aligned}
$$

Dengan mensubstitusi balik permisalan $\varphi, p$, dan $z$, diperoleh

$$
G(x, t)=\frac{1}{t} W_{\frac{\alpha-\nu}{2}, 0}\left(-x \sqrt{\frac{\rho}{E \tau^{\alpha}}} t^{\frac{\alpha-\nu}{2}}\right) .
$$

Substitusi persamaan (18) ke persamaan (16), jadi diperoleh

$$
r(x, t)=r_{0}(t) * \frac{1}{t} W_{\frac{\alpha-\nu}{2}, 0}\left(-x \sqrt{\frac{\rho}{E \tau^{\alpha}}} t^{\frac{\alpha-\nu}{2}}\right) .
$$

Selanjutnya akan dibuktikan dengan menggunakan teorema integral Cauchy bahwa $r(x, t)=$ 0 untuk $t<\frac{x}{c}$, dengan $c$ kecepatan rambat gelombang yang diasumsikan berhingga. Untuk membuktikan hal ini pandang kembali persamaan (15), dengan invers transformasi Laplacenya diperoleh

$$
r(x, t)=\frac{1}{2 \pi i} \int_{B r} e^{s t} r_{0}(s) \exp \left(-\frac{x}{c} \sqrt{\frac{\rho}{E \tau^{\alpha}}} s^{\frac{\nu-\alpha}{2}} c\right) d s .
$$

Lintasan Bromwich dapat dipilih dari $p-i \infty$ sampai $p+i \infty$ dengan $p$ sebarang bilangan real sedemikian sehingga singularitas dari integran seluruhnya berada di sebelah kiri garis $\operatorname{Re}(s)=$ $p$.

Kasus $t<\frac{x}{c}$, maka $t+a=\frac{x}{c}$ untuk suatu $a>0$, sehingga (20) ditulis menjadi

$$
r(x, t)=\frac{1}{2 \pi i} \int_{p-i \infty}^{p+i \infty} e^{s t} r_{0}(s) e^{-(t+a) \sqrt{\frac{\rho}{E \tau^{\alpha}}} s^{\frac{\nu-\alpha}{2}} c} d s .
$$

Untuk menghitung integral pada persamaan (21), dapat digunakan integrasi dengan kontur seperti yang ada pada Gambar (2.) Gambar tersebut akan memvisualisasikan proses pengintegralan Cauchy dengan membangun suatu lintasan tertutup dalam daerah definisinya dengan jari-jari $R$ menuju takhingga dan lintasan $C$ sebagai lintasan pengintegralannya. Lintasan $C$ merupakan gabungan dari tiga lintasan kecil yang dijelaskan pada gambar.

Melalui penerapan teorema integral Cauchy pada lintasan tertutup Gambar (2.) akan diperoleh hasil pada persamaan (22), hal ini sesuai sebab tidak terdapat singularitas $r(x, t)$ dalam lintasan tertutup tersebut.

$$
\frac{1}{2 \pi i} \int_{C} e^{s t} r_{0}(s) e^{-(t+a) \sqrt{\frac{\rho}{E \tau \alpha}} s^{\frac{\nu-\alpha}{2}} c} d s=0 .
$$




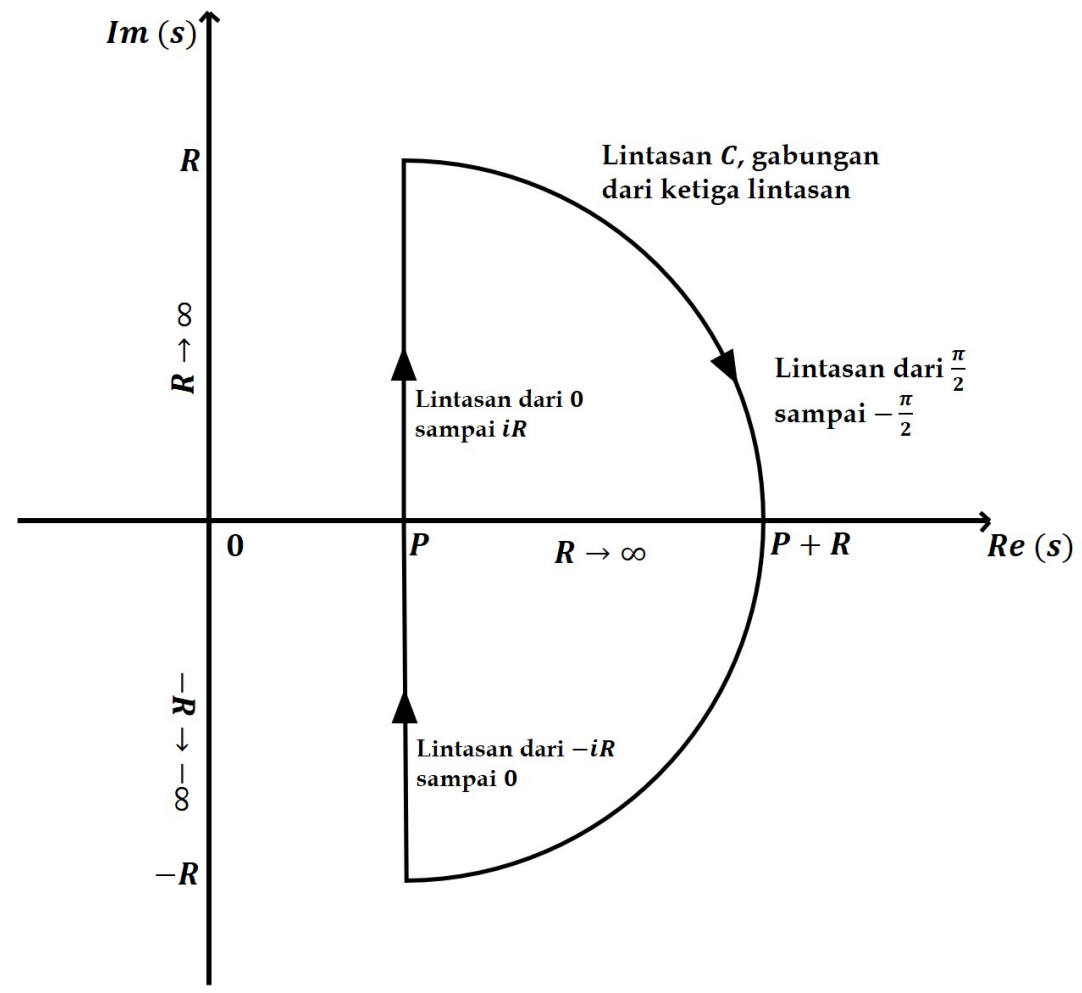

Gambar 2. Kontur Pengintegralan

Integral pada persamaan (22) dapat dipartisi menjadi tiga lintasan seperti pada persamaan (23).

$$
\begin{aligned}
& \lim _{R \rightarrow \infty} \int_{-i R}^{0} e^{(y+p) t} r_{0}(y+p) e^{-(t+a) \sqrt{\frac{\rho}{E \tau^{\alpha}}}(y+p)^{\frac{\nu-\alpha}{2}} c} d y+ \\
& \int_{0}^{i R} e^{(y+p) t} r_{0}(y+p) e^{-(t+a) \sqrt{\frac{\rho}{E \tau^{\alpha}}}(y+p)^{\frac{\nu-\alpha}{2}} c} d y+ \\
& \int_{\frac{\pi}{2}}^{\frac{-\pi}{2}} e^{\left(P+R e^{i \theta}\right) t} r_{0}\left(P+R e^{i \theta}\right) e^{-(t+a) \sqrt{\frac{\rho}{E \tau^{\alpha}}}\left(P+R e^{i \theta}\right)^{\frac{\nu-\alpha}{2}} c i R e^{i \theta} d \theta=0}
\end{aligned}
$$

Langkah selanjutnya dengan menjumlahkan dua suku pertama persamaan (23) kemudian pisahkan menjadi dua sisi seperti pada persamaan (24).

$$
\begin{aligned}
\int_{p-i \infty}^{p+i \infty} e^{s t} r_{0}(s) e^{-(t+a) \sqrt{\frac{\rho}{E \tau^{\alpha}}} s^{\frac{\nu-\alpha}{2}} c} d s= & \lim _{R \rightarrow \infty} \int_{\frac{-\pi}{2}}^{\frac{\pi}{2}} e^{\left(P+R e^{i \theta}\right) t} r_{0}\left(P+R e^{i \theta}\right) \\
& \times e^{-(t+a)} \sqrt{\frac{\rho}{E \tau^{\alpha}}}\left(P+R e^{i \theta}\right)^{\frac{\nu-\alpha}{2}} c i R e^{i \theta} d \theta .
\end{aligned}
$$

Dengan demikian integral pada persamaan (21) adalah nilai dari ruas kanan persamaan (24) 
saat $R \rightarrow \infty$. Perhatikan bahwa

$$
\begin{aligned}
& \lim _{R \rightarrow \infty} \int_{\frac{-\pi}{2}}^{\frac{\pi}{2}} e^{\left(P+R e^{i \theta}\right) t} r_{0}\left(P+R e^{i \theta}\right) e^{-(t+a) \sqrt{\frac{\rho}{E \tau^{\alpha}}}\left(P+R e^{i \theta}\right)^{\frac{\nu-\alpha}{2}}{ }^{c} i R e^{i \theta} d \theta} \\
& =\int_{\frac{-\pi}{2}}^{\frac{\pi}{2}} \lim _{R \rightarrow \infty} e^{\left(P+R e^{i \theta}\right) t} r_{0}\left(P+R e^{i \theta}\right) e^{-t \sqrt{\frac{\rho}{E \tau^{\alpha}}}\left(P+R e^{i \theta}\right)^{\frac{\nu-\alpha}{2}} c} \\
& \quad \times \lim _{R \rightarrow \infty} e^{-a \sqrt{\frac{\rho}{E \tau^{\alpha}}}\left(P+R e^{i \theta}\right)^{\frac{\nu-\alpha}{2}} c} i R e^{i \theta} d \theta .
\end{aligned}
$$

Untuk menyelesaikan persamaan (25), pandang pengambilan limit berikut

$$
\begin{aligned}
\lim _{R \rightarrow \infty} e^{-a \sqrt{\frac{\rho}{E \tau^{\alpha}}}\left(P+R e^{i \theta}\right)^{\frac{\nu-\alpha}{2}} c i R e^{i \theta}=} \lim _{R \rightarrow \infty} \frac{i R e^{i \theta}}{\sum_{n=0}^{\infty}\left(a \sqrt{\frac{\rho}{E \tau^{\alpha}}}\right)^{n}\left(P+R e^{i \theta}\right)^{\frac{(\nu-\alpha) n}{2}}} \\
=0 .
\end{aligned}
$$

Substitusikan hasil persamaan (26) pada persamaan (24) sehingga dihasilkan

$$
r(x, t)=\frac{1}{2 \pi i} \int_{p-i \infty}^{p+i \infty} e^{s t} r_{0}(s) e^{-(t+a) \sqrt{\frac{\rho}{E \tau^{\alpha}}} s^{\frac{\nu-\alpha}{2}} c} d s=0 .
$$

Dengan demikian diperoleh persamaan (28) sebagai solusi dari persamaan (11) dengan kondisi batas (4a) dan kondisi awal (4b).

$$
r(x, t)=\left\{\begin{array}{lr}
r_{0}(t) * \frac{1}{t} W_{\frac{\alpha-\nu}{2}, 0}\left(-x \sqrt{\frac{\rho}{E \tau^{\alpha}}} t^{\frac{\alpha-\nu}{2}}\right), & t \geq \frac{x}{c} \\
0, & t<\frac{x}{c}
\end{array}\right.
$$

notasi $*$ merupakan notasi konvolusi Laplace.

\subsection{Solusi $r(x, t)$ untuk parameter $0<\alpha<1$ dan $0<\nu \leq 2$ dengan menggunakan metode NILT}

Konstanta real $p$ dan bilangan bulat $m$ dipilih sehingga $\widetilde{r}(x, s)$ holomorfik pada region $R e(s)>p$, dengan kata lain $\widetilde{r}(x, s)$ tidak memiliki singularitas pada $p$ ataupun pada region di sebelah kanan garis vertikal $R e(s)=p$. Dengan menerapkan formula hasil hampiran metode NILT pada persamaan (5) diperoleh

$$
\begin{aligned}
r(x, t) \approx & \frac{\widetilde{r}(x, \operatorname{Re}(z)) e^{\operatorname{Re}(z) t}}{2 m t}+\frac{e^{\operatorname{Re}(z) t}}{m t} \sum_{k=1}^{\infty} \operatorname{Re}(\widetilde{r}(x, z)) \cos \left(\frac{k \pi}{m}\right) \\
& -\frac{e^{\operatorname{Re}(z) t}}{m t} \sum_{k=1}^{\infty} \operatorname{Im}(\widetilde{r}(x, z)) \sin \left(\frac{k \pi}{m}\right)
\end{aligned}
$$

dengan $z=p+i \frac{k \pi}{m t}$, dan galat $\epsilon(p t, m) \approx M e^{-2 m p t}, M$ adalah nilai maksimum mutlak dari $r(x, t)$ pada domainnya. 


\subsection{Contoh}

Dari data eksperimen, parameter material dari polimer Poly (ethylene-co-butene) 64 adalah $\tau=1 s, E=3 \frac{\mathrm{Ns}^{2-\nu}}{\mathrm{m}^{2}}, \alpha=0,4$, dengan massa jenis $\rho=1,5 \frac{\mathrm{kg}}{\mathrm{m}^{3}}$ yang dimodelkan oleh model fraksional Scott-Blair. Kondisi batas diketahui $r(0, t)=\delta(t), \lim _{x \rightarrow \infty} r(x, t)=0, t>0$, dan kondisi awal $r\left(x, 0^{+}\right)=\left.\frac{\partial}{\partial t} r(x, t)\right|_{t=0^{+}}=0, x>0$. Solusi analitik diperoleh dengan mensubstitusi parameter yang diketahui ke persamaan (28) yaitu

$$
r(x, t)= \begin{cases}\delta(t) * \frac{1}{t} W_{\frac{0.4-\nu}{2}, 0}\left(\frac{-x}{\sqrt{2}} t^{\frac{0,4-\nu}{2}}\right), & t \geq \frac{x}{c} \\ 0, & t<\frac{x}{c} .\end{cases}
$$

Untuk solusi analitik dengan metode NILT gunakan persamaan (29), dengan melihat singularitas dari integran menggunakan invers langsung diperoleh singularitasnya di $s=0$, maka dapat dipilih $p=0,25$, dan $m=2$ sehingga

$$
\begin{aligned}
r(x, t) \approx & \frac{\widetilde{r}(x, \operatorname{Re}(z)) e^{\operatorname{Re}(z) t}}{2 m t}+\frac{e^{\operatorname{Re}(z) t}}{m t} \sum_{k=1}^{\infty} \operatorname{Re}(\widetilde{r}(x, z)) \cos \left(\frac{k \pi}{m}\right) \\
& -\frac{e^{\operatorname{Re}(z) t}}{m t} \sum_{k=1}^{\infty} \operatorname{Im}(\widetilde{r}(x, z)) \sin \left(\frac{k \pi}{m}\right)
\end{aligned}
$$

dengan $z=0,25+i \frac{k \pi}{2 t}$.

Misal dipilih $\nu=1,5$, plot perbandingan solusi analitik dengan solusi numerik untuk $t=1, t=2$, dan $t=3$ dengan menggunakan MATLAB disajikan pada (Gambar 3.)

Pada [19] diperoleh galat untuk metode NILT adalah sebesar $\epsilon(p t, m) \approx M e^{-2 m p t}, M$ adalah nilai maksimum mutlak dari $r(x, t)$. Dari Gambar (3.) untuk tiga nilai $t$, amplitudo difusigelombang menurun (meredam) seiring dengan bertambahnya nilai $t$, hal ini sesuai dengan sifat material viskoelastis yang segera kembali kebentuk semula atau mempertahankan bentuknya. Dengan demikian amplitudo gelombang pada $r(x, t)$ ketika $t=1$ dapat dipilih menjadi nilai $M$, yaitu $M=0,3$. Karena $p=0,25$ dan $m=2$, maka akan diperoleh untuk $t=1, \epsilon \approx 0,3 e^{-2(2)(0,25)(1)}=0,11$, untuk $t=2, \epsilon \approx 0,3 e^{-2(2)(0,25)(2)}=0,04$, untuk $t=3, \epsilon \approx 0,3 e^{-2(2)(0,25)(3)}=0,015$. Nilai $\epsilon$ akan bertambah kecil ketika $t$ semakin besar, hal ini menunjukkan bahwa ketika $t$ membesar solusi NILT akan menghampiri solusi analitik dengan sangat baik. Pada contoh kasus ini dapat dilihat bahwa untuk $x>10$ nilai $r(x, t)$ hampir seluruhnya nol untuk $t$ nilai berapapun, sesuai dengan solusi analitik yang diperoleh pada persamaan (30).

\section{KESIMPULAN DAN PENELITIAN LANJUTAN}

Solusi analitik persamaan difusi-gelombang fraksional pada media viskoelastis yang memenuhi nilai batas Signalling dapat diselesaikan dengan mengarahkan solusi ke fungsi Wright. Solusi analitik diperoleh untuk parameter $\alpha<\nu<\alpha+2$ dengn $0<\alpha<1$, diluar nilai tesebut digunakan metode NILT. Menemukan solusi persamaan difusi-gelombang secara analitik sangat efektif mengingat belum tersajinya solusi analitik unuk persamaan disufi-gelombang dalam bidang teknik. Penelitian lanjutan yang dapat dilakukan adalah membuat perumuman solusi persamaan difusi-gelombang tanpa adanya pembatasan parameter. 

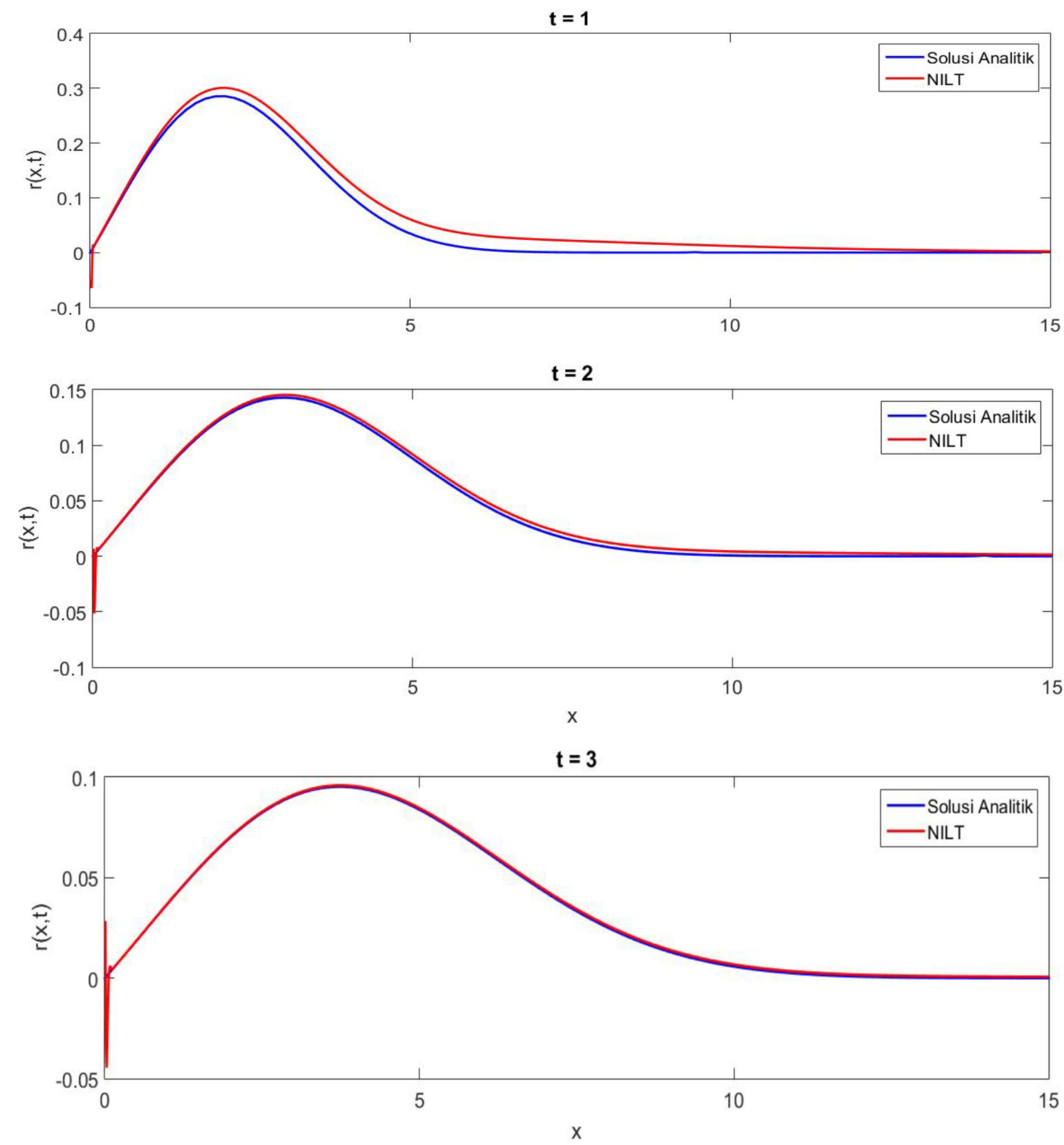

Gambar 3. Plot $r(x, t)$ dengan $\nu=1,5$ untuk $t=1, t=2$, dan $t=3$

\section{REFERENSI}

[1] Nutting, P.G. 1921: A new general law of deformation, Journal of The Franklin Institute, Vol. 191, Edisi 5, 679-685

[2] Blair, G. dan Reiner, M.. (1951). The rheological law underlying the Nutting equation. Flow Turbulence and Combustion - Flow Turbul Combust. 2. 225-234. 10.1007/BF00411984.

[3] Rogosin, S. dan Mainardi, F. 2014: George William Scott Blair the pioneer of fractional calculus in rheology. Communications in Applied and Industrial Mathematics, Vol. 6, No. 1.-481; ISSN 2038-0909; DOI: 10.1685/journal.caim.481.

[4] Nigmatullin, R. R. 1986: The realization of the generalized transfer equation in a medium with fractal geometry, Physica Status Solidi B, 133, 425430; DOI: 
10.1002/pssb.2221330150.

[5] Mainardi, F., Luchko, Y., dan Pagnini, G. 2001: The fundamental solution of the spacetime fractional diffusion equation, An International Journal for Theory and Applications, Vol. 4, No. 2, 153-192; ISSN 1311-0454.

[6] Mainardi, F., dan Pagnini, G. 2003: The wright function as solutionsof the time-fractional diffusion equation, Applied Mathematics and Computation, Vol. 141, Edisi 1, 51-62; dx.doi.org/10.1016/S0096-3003(02)00320-X.

[7] Povstenko, Y. 2011: Non-axisymmetric solutions to time-fractional diffusion-wave equation in an infinite cylinder, Fractional Calculus and Applied Analysis, Vol. 14, No. 3, 418-435; DOI: 10.2478/s13540-011-0026-4.

[8] A. Bradji, A new analysis for the convergence of the gradient discretization method for multidimensional time fractional diffusion and diffusion-wave equations, Computers and Mathematics with Applications (2019),https://doi.org/10.1016/j.camwa.2019.11.001.

[9] Y.Zheng, Z. Zhao, The time discontinuous space-time finite element methode for fractional diffusion-wave equation, Appl. Numer. Math. (2019), https://doi.org/10.1016/j.apnum.2019.09.007

[10] Tramontana V, et al. An application of Wright functions to the photon propagation. J Quant Spectrosc Radiat Transfer (2013), http://dx.doi.org/10.1016/j.jqsrt.2013.03.008

[11] Elsaid, A., Latief, M.S.A, Maneea, M. 2016: Similarrity Solutions for Multiterm TimeFractional Diffusion Equation, Advances in Mathematical Physics, Hindawi Publishing Corporation, http://dx.doi.org/10.1155/2016/7304659.

[12] Mainardi, F. 2010: Fractional calculus and wave in liear viscoelasticity, An introduction to mathematical models, ISBN-101-84816-329-0, London, Imperial College Press.

[13] Podlubny, I. 1999: Fractional differential equation, Mathematics in Science and Engineering, Vol. 198, ISBN 0-12-558840-2, San Diego, California, Academic Press.

[14] Wong, R. dan Zhao, Y.-Q. 1999: Smoothing of Stokes' discontinuity for the generalized Bessel function, Proceedings of the Royal Society of London A: Mathematical, Physical and Engineering Sciences 455, 1381-1400; DOI: 10.1098/rspa.1999.0365.

[15] Choksi, H., dan Timol, M.G., 2014: Similarity solution for partial differential equation of fractional order, International Journal of Engineering and Innovative Technology (IJEIT), Vol. 4, Edisi 2, ISSN 2277-3754.

[16] Sheng, H., Li, Y., dan Chen, Y.-Q. 2010: Application of numerical inverse Laplace transform algorithms in fractional calculus, Journal of The Franklin Institute, 348, 315-330; DOI: 10.1016/j.jfranklin.2010.11.009.

[17] Rani, D., Mishra, V., Numerical Inverse Laplace Transform based on Bernoulli Polynomials Operational Matrix for Solving Nonlinear Differential Equations, Results in Physics (2019), doi: https://doi.org/10.1016/j.rinp.2019.102836 
[18] N.U. Khan, T. Usman and M. Aman, Some properties concerning the analysis of generalized Wright function, Journal of Computational and Applied Mathematics (2020), doi: https://doi.org/10.1016/j.cam.2020.112840.

[19] Brancik, L., dan Smith, N. 2015: Two approaches to derive approximate formulae of NILT method with generalization, IEEE, DOI: 10.1109/MIPRO.2015.7160256. 